\title{
ДЕТЕРМИНАНТЫ СМЫСЛА КОНЦЕПТА «СОВРЕМЕННАЯ ЭКОНОМИКА»
}

\section{А. А. Атанов}

Байкальский государственный университет, г. Иркутск, Российская Федерация

\author{
Информация о статье \\ Дата поступления \\ 9 июня 2017 г. \\ Дата принятия к печати \\ 28 июля 2017 г. \\ Дата онлайн-размещения \\ 15 сентября 2017 г.

\section{Ключевые слова \\ Философия; психология; экономика; современный; современная экономика; сущность; процесс; диалектика; концепт}

\begin{abstract}
Аннотация
Статья посвящена концептуальному анализу неравновесных понятий, в которых сущностные основания смещены в отношении позиции сил, причем выделяются не только процессы, но и изолированные сущности. К таким понятиям относится понятие «современная экономика». В нем соединены две сущности, выражающие себя через соответствующие смыслы. Первая относится ко времени. Вторая к процессу. Если говорить в системе общностей, то временные конструкции обладают более общим характером, чем процессы, связанные с социальностью. В статье анализируется характер экономических процессов применительно к либидозным и мортидным структурам. Проводится исторический и смысловой анализ. Изучается, в какой степени «дух» капитализма капиталистичен и связан ли он с экономикой. Базовые методы исследования - диалектический, структурный, исторический. Проводится анализ психоаналитических концепций экономики, понятий «психовласть», «психиатрическая власть». Все эти подходы находят свое место при анализе понятия «современная экономика».
\end{abstract}

\section{DETERMINANTS OF SENSE OF THE «MODERN ECONOMY» CONCEPT}

\author{
Andrei A. Atanov \\ Baikal State University, Irkutsk, Russian Federation
}

\section{Article info}

Received

June 9, 2017

Accepted

July 28, 2017

Available online

September 15, 2017

\section{Keywords}

Philosophy; psychology; economics; contemporary; modern economy; essence; process; dialectics; concept

\begin{abstract}
The article deals with the conceptual analysis of unbalanced notions within which essential foundations are shifted towards the position of strength and, what is more, not only processes but also separate essences are regarded. Among such unbalanced notions there is a notion of «modern economy» that combines two entities reflecting corresponding senses, the first one refers to time and the second one - to process. Speaking about the system of entities, temporal constructions are of less general character than processes referring to sociality. In the paper an analysis of nature of processes running in the economy is performed in terms of libido and mortido structures. Semantic and historical analyses are also carried out. The paper addresses an issue of the extent the spirit of capitalism is capitalistic to and whether it is related to the economy. Dialectic, structural and historical methods are used as basic research methods. In the paper an analysis of psychoanalytical conceptual ideas of economy, such as "psychopower» and "psychiatric power», is performed. The above mentioned approaches are applied to analyze the notion of «modern economy».
\end{abstract}

Любое описание понятия, связанного с социальной жизнью, включает ряд ограничений:

1. Всегда есть понятие более высокого уровня или более всеобщего характера, ко- торое и детерминирует основания смысла, закладываемого не во всеобщем как категории знания и философского размышления, а во всеобщем, определенном человеческой 
жизнью или социумом. Такое понятие может претендовать на статус общности в отношении всеобщего, но не на статус всеобщего во всеобщем. Например, понятие «закон» имеет всеобщий характер, тогда как понятие «социальный закон» носит общий характер из-за ограниченности в масштабах Вселенной социума и из-за ограничений, связанных с природой человека.

2. Система понятий в этой системе, не претендующей на всеобщее, закладывается либо как иерархическая, либо как система особенного, т. е. как единство общего и единичного с указанием на общее. Акцент в данности, закладываемой через такую понятийную структуру, делается или на иерархию, или на особенности данности, а не на реальность данности (исчезает основание для онтологической реконструкции).

3. Из этого следует, что необходимо знать систему ограничений каждого из понятий, включенных в процесс взаимодействия, исходя из характеристик реальности, а не только желаемости процессов, которые «должны» случиться. В терминологическом плане речь идет тогда не о реальности, а только о возможности и действительности, раскрываемых через систему каузальных связей.

Если мы хотим описать экономическую систему, характеризующуюся свойством стабильности, - это одно, если ее особенностью является нестабильность - совершенно иное. Как видим, возникает терминологическая нестыковка: стабильность и нестабильность - это свойства экономических систем или их особенность? В классических философрских системах достаточно часто используется диалектика одного и иного. Можно предположить, что на уровне перехода одного понятия в другое мы можем создать основания для перехода стабильности в нестабильность, и наоборот. К сожалению, в таком рассуждении прячется логическая ошибка. Речь ведь идет о стабильной и нестабильной экономических системах, а не о понятиях «стабильность» и «нестабильность».

Основание стабильности или нестабильности может быть определено как общее, если этот процесс указывает на возможность взаимного перехода, или же мы можем признать существование этих понятий в виде изолированных сущностей, которые не даны нам через процесс взаимодействия (по сути дела, отсутствуют основания для связи и для отношения). При этом нужно учитывать, что необходимость анализа сохраняется, даже если это изолированные сущности, тогда анализ производится исходя не из процесса взаимодействия, а из выделенных и четко закрепленных единичных оснований, которые в логической форме выражаются как обоснованные. Тем самым мы решаем задачу как задачу, определяемую общностью или же типом связи, через который раскрываются свойства системы. Введение изолированных сущностей в этом случае - более легкий способ решения задачи.

Чтобы было понятно, о чем идет речь, небольшой комментарий. В философии Гегеля используется понятие «свобода» [1, с. 288-311]. Но сам Гегель уточняет, что применительно к человеческой жизни понятие абсолютной свободы использовать нельзя, так как существует система вызванных самой человеческой жизнью ограничений, следовательно, реализация абсолютной свободы приводит не к жизни, а к смерти и распаду. В любом случае нужно четко понимать, что соединение двух сущностей - свободы и человека - наталкивается на ограничения, связанные с природой человека, хотя на первый взгляд кажется, что два этих понятия - «человек» и «свобода» - совместимы. На самом деле они не совпадают в основаниях, отсюда их различная определенность в процессе взаимодействия. Ограничение свободы связано с ограниченностью не свободы, а человека.

Если мы продолжим наши рассуждения, то введение понятия эфрфективной или неэфрфективной экономики опирается на ту же самую дихотомию определения: или мы имеем дело процессом, или с изолированными сущностями.

Чтобы было понятно, о чем идет речь, объясню, что значит понятие «одно». Одно - само по себе, одно - ни иное, ни другое. Между «одно» и «иное» нет взаимодействия, если вводить определение через «одно». Простейшее объяснение: одно - не иное. В нем нет взаимодействия, множества и существования, все это темы, относящиеся к иному. Поэтому одно - сущность, лишенная явления и всяких оснований для основы. Диалектика помещает одно и иное в единую систему, но даже в диалектике выводы делаются для иного в одном и одного в ином. По сути дела, если мы имеем дело с реальным миром, то в нем выражается или процессуальность, или сущностное единство, каждое из этих понятий опирается на совершенно отличную от другой систему оснований. Первичное отношение, закладывающее систему человеческой жизни, - это отношение «Я» - «Другой». На индивидуальном уровне именно здесь закладываются отношения эмпатии и социальности. Отношение - это 
существование одного через другое. Тогда определение экономики как эффективной, неэффективной, стабильной, нестабильной, определенной, неопределенной и т. д. все-таки зависит от сущностных оснований другого порядка, относящихся совсем не к экономике, а к эфффективности, стабильности, нестабильности и т. д. Эти понятия существуют совершенно в других общностях, чем понятие «экономика». Сущность этих понятий указывает на возможное включение иной сущности, или же сущность не обладает достаточными возможностями для включения иной сущности, или же, что более вероятно, эти сущности являются несоединимыми.

Чтобы было понятно, о чем идет речь, возьмем два понятия - «современный» и «экономика». Современный относится ко времени, которое ограничено ситуацией здесь и сейчас, но при этом «современный» выступает и как связанное понятие, относящееся к будущему, а не к прошлому, прежде всего посредством новизны, это как молоденькие весенние листочки (свежие, чистые, новенькие), а не пропыленные листья лета и опадающие, умирающие листья осени. Дело не только в листочках, но и в том, какое время года сейчас. Зимой у «современного» дерева просто не будет листьев, тогда сущностью, взаимодействующей с природой, оказывается дерево, а не лист, ведь лист определяется природой и жизнью дерева, которое, в свою очередь, гармонизировало свою жизнь в отношении природных циклов и условий, принимаемых как безусловные.

Новый порядок вещей (любая новизна) в человеческой жизни определен не традицией, а более общими законами, которые или допускают вхождение нового, или же нет. У того же Гегеля есть наблюдение, касающееся Наполеона. Если бы Наполеон проиграл во время борьбы с революцией или же принимал обывательскую мораль, он никогда не стал бы «действительным» Наполеоном, проложившим новый путь, и этот путь, в силу того что стал действительным, изменил всю природу морали человека, которая приобретает исторический характер, сущность ценностей находится не только в природе человека, но и в сущностях, занимающих в иерархии более высокий порядок, человек лишь раскрывает истинное положение вещей, делая его актуальным для себя [2, с. 233-362]. У моего товарища есть дивное наблюдение по поводу Родиона Раскольникова: Раскольников на самом деле хочет стать старухой-процентщицей, а не Наполеоном. В действительности, если бы Раскольников принял себя и пошел по пути обретения денег ростовщичеством, никакое убийство ему не понадобилось бы, простое желание иметь деньги перешло бы в форму ростовщичества со всей присущей этой сфере спецификой. Ведь богаче бабки-процентщицы никого в Петербурге не было? Манило не богатство, манили особенности старухи-процентщицы.

У Г.К. Честертона есть очень точное наблюдение, касающееся новизны: «Спросим себя о том, чего на самом деле хотим, а не о том, о чем нас учат последние законодательные меры, или что мы должны хотеть, согласно недавним размышлениям мыслителей, или чего однажды захотим, согласно прогнозам общественных предсказателей. Если у нас будет социализм, то пусть он будет социальным, отличаясь от всех торговых компаний, существующих сейчас. Настоящий портной, работающий над заказом, всегда исходит из того, что ткани на пальто у него должно быть больше, а не ровно столько, сколько по факту уйдет на пошив пальто. Настоящий практичный государственный деятель никогда не приспосабливается к существующим условиям, он осуждает такие условия как неподходящие» ${ }^{1}$. Эта иллюстрация из Честертона позволяет понять, что ключевой критерий новизны - это неудовлетворенность тем, что есть сейчас.

Возникает резонный вопрос: экономика - это про время? Судя по всему, темпоральность является гораздо более общим понятием, чем экономика. Время - более общее вселенское основание, чем социально выраженная экономика, связанная с удовлетворением потребностей человека и с ключевым понятием «благосостояние». Даже если мы предположим, что время в реальности не существует, а является лишь специфической человеческой формой восприятия действительности, и то эта форма имеет гораздо более общий характер, чем экономика. Тогда, когда употребляется словосочетание "современная экономика», в смысловой форме акцент смещен не на экономику, а на понятие "современность», то же самое будет происходить и с понятиями «определенность» и «неопределенность». Можно предположить, что, возможно, понятие «эффективность» уже включено в экономику и связано с ее сущностью, но, к сожалению, понятие «эффективность» имеет отношение к человеческой деятельности вообще, причем взятой в критериях действенности.

URL: www.spectator.co.uk/the-week/leadingarticle/8789981/glad-tidings. 
Может быть, поискать понятие, которое будет отражать систему взаимодействия экономики как общего понятия и чего-то другого, более локального и заключенного в экономике, вместе с тем создавая единство, где экономика выступает как самодостаточное образование? Тогда что это? Если это основание не будет найдено, то сущность экономики необходимо искать не в экономике. А в чем? Или же мы можем предположить даже в экономической системе существование единичных сущностей, а не процессуальных отношений? Или все гораздо проще: процесс и запускает наличие изолированных сущностей? Тогда мы и заходим в процессы не экономические, а качественно совершенно иные, в большей степени относящиеся ко всеобщему, а не к общему экономики. В этом случае все становится очевидным: мы занимаемся изучением современности, неопределенности, определенности, эфрфективности как общих понятий локальной системы, лишь указывающих на экономику. Сущность не в экономике, а в первичном отношении бытийственного плана "одно» - «иное» и социально-мировоззренческого отношения «Я» - «Другой». Идет указание на сущность, которая и есть процесс.

У Гегеля мудрость соединена с двумя факторами, первый из которых - совершенное знание себя; второй - человек, совершенно удовлетворенный тем, что он есть.

Люди, как правило, недооценивают трудности, связанные с удовлетворенностью, и переоценивают трудности, связанные со всезнанием. Нравственное совершенство, воплощаемое мудрецом, означает, что его жизнь служит образцом как для него самого, так и для других, т. е. мудрец удовлетворен тем, что есть. Признание всеми означает то, что мудрец отождествлен с самосознанием, а отсюда идет отсылка к совершенному знанию себя [2, с. 422-435; 3, с. 339-342].

Для чего приведена гегелевская аргументация? Для того чтобы четко понимать, что понятие обретает значимость, когда подключена определенность «все», соединенная с самосознанием, только тогда может быть оформлено понятие. Понятие у Гегеля не субъективно, а объективно в своей данности. Обретая понятие, мы обретаем самосознание, но только как всеобщее. Отсылка к экономике и к любой человеческой деятельности возможна только через всеобщее, но самосознающее; гениальность Наполеона в умении приходить к понятиям, которые уже есть в окружающей человека действительности как законы, принципы, категории, бытийственно определенные и указывающие на человеческую жизнь в ее предельном содержании. Поиск подтверждает или не подтверждает форму понятия, но только в нравственном совершенстве, знании и удовлетворенности.

Если мы хотим определить современную экономику, необходимо определить понятие "современность», но это весьма сложно сделать. Поэтому в смысловом плане часто уходят к определению новых технологий, которые влияют на экономику. По сути дела, появляется технологическая экономика, где ведущим понятием становится "технология». Приравнять друг к другу по объему и по содержанию понятия «современность» и «технологии» вряд ли возможно. "Современность» - понятие, связанное со временем и социумом в целом, тогда как «технологии» касаются системы познания, науки, инженерии, т. е. "технологии» имеют гораздо более избирательный характер, причем детерминируемый системой деятельности, а не общностью социума и времени. Отсюда в экономической системе, определяемой «технологиями», гораздо более высокий уровень энтропии и неопределенности. Это связано с тем, что число создателей новых технологий на планете Земля гораздо меньше, чем число пользователей этих же технологий. Для иллюстрации, сколько людей на планете могут разработать новый компьютерный процессор? Думаю, максимум несколько сотен, тогда как компьютерами пользуются миллиарды, все другие направления развития технологий идут в русле заложенных тенденций, т. е. «современность» носит вполне определенный характер, но это не определенность "современности», а определенность «технологии», мышление большинства людей не перестроено, оно опирается на стереотипы школьного и вузовского образования, если принимать эти стереотипы за систему знания, то они носят архаичный характер в силу того, что идет отсылка к прошлому. Дело не в образовании как в системе знания, дело в образовании, способствующем или не способствующем развитию творческих способностей. Образования, способствующего развитию творческих способностей, в настоящий момент не существует, творческие личности - исключения из правил, но при этом принимающие правила объективного мира, где действуют законы и закономерности, относящиеся в том числе и к человеческой природе. Понять природу человека можно, только признавая все особенности человека, все скрытые (открытые) части. Если смысло- 
вая определенность развития акцентируется человеком посредством выделения циклических процессов, зайти в современность, даже технологическую, невозможно. В смысловом плане у нас появляется возможность соотнести два этих понятия - «технологии» и «современность» - только со всей присущей им системой ограничений.

К технологиям относятся такие общие основания, как избирательность, единичность, особенность, неопределенность. К современности - всеобщность (в силу всеобщности появляется возможность включить в состав системы как состояние определенности, так и состояние неопределенности), в характере связей современности и технологий появляются общие основания, но в этой общности усиливается характер неопределенности из-за специфики понятия «технологии», носящего избирательный характер. Акцент смещается в природу человеческого творчества. Что выбирает «современность» в этом творчестве, делая его актуальным через «технологии»? Возможность выбора тогда носит не только личный характер, она определяется тенденциями "современности». Не в этом ли состоит высшая значимость? Попытаемся разобраться с технологиями, которые претендуют в системе экономической реальности на звание современных.

Можем перечислить современные технологии, влияющие на экономику. К их числу относятся роботизация, к чему приведет ее применение, мы увидим в ближайшем будущем. Вполне возможно, некоторые страны станут впервые в истории человечества цивилизациями роботов. Следующая тенденция - это кастомизация производства: производится только то, на что есть заказ, на конвейере не модель, а множество марок, в результате производство индивидуализируется. Пример: современное производство автомобилей со множеством индивидуальных особенностей, в кастомизированном производстве будет производиться не модель, а индивидуализированное изделие. С процессом производства индивидуальных вещей связана 3D-печать, которую можно использовать практически во всех производственных областях. Отсюда в систему производства вводится понятие изделия-прототипа. Следующая область технологий — большие данные. Можно визуально определить характеристики объектов экономики по количеству выбросов, количеству фур, строительной активности, объему отвалов, характеристикам транспортной системы, объему товарных и сырьевых запасов, трафику рабочей силы и грузов. Маленькая особенность указанной технологии - для анализа деятельности крупных предприятий нужно делать 2,2 млрд фотографий. Сам спутник, занимающийся передачей данных, стоит недорого, сложность заключается в их обработке, для этого нужны новые алгоритмы. Но информацию, причем реальную, спрятать уже нельзя, так как она объективируется по четко выделенным критериям, иллюстрацией которых служит массив информации, качественно другой, чем эмпирические данные, - это одна из областей применения больших данных. В мире 6 млн километров дорог, более 50 тыс. крупных судов и только 50 крупных портов, что более информативно? Думаю, ответ очевиден, - это тоже область применения больших данные. Следующая область применения - «Интернет вещей и станков», где все технологические структуры образуют целостность.

В качестве вывода можно сказать, что экономика в этих областях оказывается вторичной структурой, производной от научно-технического процесса и человеческого творчества. Структура производства приобретает индивидуализированный характер, ориентированный на "другого», отсюда измененные отношения обмена, распределения и потребления. Современность включается через совершенно другой, неэкономический механизм, но вместе с тем никто не может убрать традиционные экономические структуры, связанные с эфффективностью и производительностью.

Я сомневаюсь, что большие данные о Зимбабве будут носить экономический характер, скорее всего, будут учитываться другие параметры, но эти параметры вряд ли кого-нибудь сильно заинтересуют. Есть места попритягательней, говоря другим языком, более современные, с редуцированной системой человеческого творчества и деятельности. Культура Зимбабве очень интересна, но ее изучением займутся антропологи, интересующиеся не возникновением нового, а уже существующим, включенным в культурные коды, причем изучаться всё будет при помощи методологии структурализма, постструктурализма, френоменологии, т. е. посредством включения традиционной культуры в совершенно другие культурные коды иной цивилизации, где основанием стала не традиция, а наука.

Можно перейти к системе экономики, которая позиционирует себя как общество потребления, но, как мы уже убедились, функция системы является производной от 
ее структуры. Целостного описания не получится, если мы не воспроизведем систему, возможно, исходя из других элементарных оснований. Воспользуемся структурами мортидо и либидо, широко известными в системе современной психологии и психотерапии. Поскольку мы говорим об экономике, она всегда концептуальное основание, тесно связанное отношениями присутствия с человеком и человеческой природой. Либидинальная экономика, основанная на маркетинге, по мнению Стиглера, производит психовласть. Психовласть «контролирует индивидуальное и коллективное поведение потребителей, канализируя их либидинальную энергию к товарам» [4, с. 232]. По сути дела, создается система «нормальности», но не как человеческой нормы, а как нормы рынка. Под эту рыночную норму и начинает адаптироваться поведение человека. Норма выражается не как субъектная, а как объектная, но важны не постоянно меняющиеся объекты, а влечение к ним. В. Мазин и А. Погребняк в книге «Незнайка и космос капитализма» [5, с. 89-90] определяют этот процесс как переход от желания к влечению, причем траектория желания оказывается криволинейной, скользящей по объекту, либидо направлено на циркуляцию потребления как такового, а не на удержание объекта.

Следующим шагом в развитии потребления будет превращение влечения в инстинкт, психологическое превращается в биологическое, возникает необходимость в производстве индивидов, наделенных базовым инстинктом потребления.

Одна из особенностей капитализма - это тяга к перепроизводству. Общество легко может быть определено как капиталистическое, если оно заточено на потребление, если данная черта отсутствует, мы имеем дело с архаичной производственной системой. Легко объяснимой становится и тяга к техническим объектам. В достаточно старой книге М. Хоркхаймера и Т. Адорно «Диалектика просвещения», написанной в 40-е гг. XX в., задолго до революции гаджетов, отмечается, что происходит «самоотчуждение индивидов, вынужденных телесно и духовно формировать себя в соответствии с мерками технической аппаратуры» [6, с. 46]. Возникает парадоксальное единство: передовая экономика в свое основание кладет примитив?

Но это не так, до уровня потребителя еще надо развиться, т. е. жизнь потребителя происходит в особой среде, и социальной, и экономической. Указанная среда характеризуется несколькими базовыми критери- ями: технологическим; организационным; психологическим; социальным. То есть «потребляющий примитив» адаптирован к очень сложной системе воздействий и должен поддерживать эту систему, но тогда система не столь однородна, ибо включает в себя, кроме потребителя, еще и создателей технологий, организаций, а также большие группы индивидов, поддерживающих всю систему в рабочем состоянии. Отсюда вывод, что к обществу потребления не так уж легко перейти. Архаичные фрормы производства этому никак не способствуют. Психовласть, которая хорошо знает либидозные основания человека и умеет перенаправлять и канализировать либидо, примитивной точно не назовешь. Авторство в создании маркетинга как целостной системы принадлежит племяннику 3. Фрейда Э. Бернейсу. Экономика в развитых странах Запада с его легкой руки стала либидинальной экономикой. Тогда существует множество фракторов, влияющих на экономику, которые не могут быть проанализированы при помощи классического экономического инструментария.

«Психовласть» - достаточно современный термин. Если мы взглянем на историю вопроса, то «психовласти» предшествовало понятие «психиатрическая власть». Это понятие, «психиатрическая власть», было весьма хорошо проработано и изучено М. Фуко. Он в книге «Психиатрическая власть» отмечает, что основной функцией психиатрической власти по отношению к безумию является фрункция оператора, своего рода интенсификатора реальности, т. е. эта власть может быть определена как сверхвласть реальности. Можно зайти в эту тему косвенно, через оформление психиатрического «лечения». М. Фуко начинает свой анализ именно с этих проявлений. Процитируем М. Фуко [7, с. 170-171].

Если говорить о начале психиатрического лечения, то лечения нет вовсе, и выздоровление больных ожидается как некий процесс, если не самопроизвольный, то во всяком случае автоматически реактивный, непосредственно обусловленный комбинацией четырех элементов: во-первых, больничной изоляции; во-вторых, медикаментов физического, физиологического характера - опиатов, лауданума и т. д.; в-третьих, ряда специфически больничных принудительных мер дисциплины, подчинения внутренним правилам, определенного рациона, режима сна, бодрствования и труда, орудий фризического принуждения; и в-четвертых, своего рода психофизического лечения, карательного и вместе с тем терапевтического, - прием 
душа, кресло-качалка и т. п. Сочетание этих элементов и определяло рамки лечения, от которого ожидали, не задумываясь ни о его объяснении, ни о теории, выздоровления больных. В замечании к данному тексту М. Фуко отмечает, что это был код, но не языковой код означающих конвенкций, а код тактический, позволяющий установить определенное соотношение сил и раз и навсегда утвердить его. Обратите внимание, что есть не просто данность, а данность, сопровождаемая кодом, т. е. воспроизводя код, мы воспроизводим и данность. По сути дела, мы оказываемся в сверхреальности, причем для посвященных у этой данности есть смысл.

Bсе эти рассуждения ничего не напоминают? Здоровье человека определяется теми правилами, которые он принимает относительно себя самого, если же этих правил нет, они навязываются как фрорма принуждения к здоровью. То есть ты сам для себя можешь стать больницей или же больница догонит тебя как внешняя форма отвращения тебя от твоего же собственного безумия. Если отвергаются правила по поводу себя, вступают в действие правила внешнего принуждения. Не бывает здоровых людей, как цинично говорят врачи, бывают недообследованные. В теме, поднимаемой М. Фуко, нет места для врачей, есть некая форма не лечения, а рамок лечения. Принуждение идет косвенным образом. Не в этом ли заключается мортидное основание общества потребления, есть правила, которые ты отменить не можешь, если ты сам полез диктовать волю внешнему миру. Либидо в потреблении, мортидо в организации социальности. Стальная рука в бархатной перчатке.

Изначально предложенная в этой статье концепция, что нужно анализировать более широкое понятие, такое как «современный», а не «экономика», становится все более актуальной. Можно сказать, что проще проанализировать понятие «современная экономика», но, увы, это понятие по своей структуре неравновесное, смысловые акценты определены «современностью». С методологической точки зрения автор этой статьи когда-то предложил использовать концептуальную форму при анализе экономических явлений. Предложенная методология становится актуальной, так как концепт содержит в себе структуру не значений, а смыслов, поэтому выступает не только формой познания, но и формой истолкования, поскольку в его состав входят процедуры понимания, закладывающие основания для междисциплинарного подхода [8, с. 20-291]. Нам необходим переход к обществу потребления исходя из системы человеческой действительности, чтобы понять, почему реальность становится сверхреальной. Поговорим о духе капитализма, который зарождался совсем не как капитализм.

Чтобы было понятно, о чем идет речь, приведем несколько исторических примеров из области, где зарождался «дух» «капитализма». Такой выдающийся деятель эпохи Реформации, как Меланхтон, переходит к непосредственному рассмотрению самй нравственной действительности, т. е. для него эта действительность абсолютно актуальна. Косвенно процитируем Меланхтона по В. Дильтею «Воззрение на мир и исследование человека со времен Возрождения и Реформации» [9, с. 76-185]. Тезисы, формулируемые Меланхтоном, звучат так:

1. Христианское совершенство состоит в том, что каждый человек в истинной вере служит своей профессии. Первоначальная мысль Лютера состояла в том, что вера выражается через деятельность в миру, сорера дела веры - это мирское общество и его устройство. Отсюда и используемое Меланхтоном понятие «призвание». Это понятие в протестантском вероисповедании использовалось и применялось в противовес негативной католической святости. Негативное - это не отрицательное, негативное - это то, что относится к фотографическому негативу, позитив в этом контексте ни плохо, ни хорошо, просто другая сторона фотографии, причем исторически первым был негатив.

2. Теперь что касается высказываний Меланхтона о браке и воспитании детей. Брак для Меланхтона есть фундамент человеческого общества и школа для развития чувства общности. Холостякам, по его мнению, редко свойственно понимание жизни и служение общему благу. Брачный союз, по его концепции, высшая степень дружбы. Иллюстрацией этих тезисов служат картины А. Дюрера о жизни Марии, где изображен плотничающий Иосиф и в том же помещении кормящая ребенка Мария. Здесь господствует чувство красоты труда, профрессии и общности обязанностей в браке.

3. Достоинства знания и школы. Учителя всей Земли должны образовать единый союз, свободный от тщеславия и пребывающий на службе науки. Однажды Меланхтон сказал, что вне университета вообще нет жизни.

4. Дела экономической и политической жизни - добрые дела и служат в благочестивом человеке подлинным почитанием Бога. Поэтому созерцательная жизнь монахов тщетная борьба с природой. В собственности 
и ее различном распределении Меланхтон видит угодную Богу границу эгоизма.

5. Естественный свет нашей совести внушает нам уверенность в существовании неизменного, незыблемого нравственного закона, заложенного в нашу душу Богом. Аргументация моральной философии является лишь развитием содержащегося в человеческой природе.

6. Отождествление естественного закона с законом Моисея присуще как Лютеру, так и Меланхтону. В естественный нравственный закон входит познание Бога, послушание Ему и утверждение человеческого общества ради Него. Единственное соответствующее этому закону свойство воли есть добродетель.

7. Естественный нравственный закон является неизменным и повсюду значимым правилом порядка в человеческом обществе. Вера придает человеку суверенность по отношению к миру, но не посредством обособления от него, а посредством простой деятельности человека для осуществления дела Божьего вместо Него. В узком понимании справедливости нормы управляют действиями и позволяют отличить доброе от злого. Справедливость в широком понимании для Меланхтона - это единство социальных добродетелей. Он понимает ее как послушание всему законодательству государства, управляемого подобающими законами (это вариант по Аристотелю), подчинение всех сил разуму (это вариант Платона) или же сохранение установленного Богом порядка. (Бог не создавал смерть - тогда божественный порядок в отходе от первородного греха, где смерть и служит средством отделения. Смерть, где твое жало? Ад, где твоя победа?)

Как видим, то, что позднее М. Вебер назовет протестантской этикой и свяжет с духом капитализма, к собственно капитализму не имеет никакого отношения, это формы организации общественной, духовной и социальной жизни, которые потом были перенесены в экономическую действительность, став правилами ее организации, но при этом видоизменившись [10, с. 7-548]. Ведь дьявол, как всегда, прячется в деталях, можем перечислить употребляемые Меланхтоном понятия: разум, единство права и морали, сохранение божественного порядка, вера, естественный закон, социальная добродетель, совесть, брак, дружба, призвание, собственность. В современном капитализме эти понятия начинают стремиться к значению, заложенному Меланхтоном, по сути дела, работает концепция признания естественных законов, а не только система получения при- были. Акцент смещен на душевную жизнь человека, добродетель - это система необходимостей, а не принцип прекраснодушия. Душа тогда прекрасна, когда признает необходимости, заложенные в состав собственной природы. Какая на самом деле человеческая душа? Ведь упомянутое нами понятие «либидо» оказывается работающим только тогда, когда опирается на хорошо развитое мортидо. Что за мортидо прячется за либидозной экономикой потребления? Ведь у Меланхтона, как можно видеть из его тезисов, везде присутствует тема единства, если явление не воспроизведено как единство, значит, в нем присутствуют фригуры умолчания. Куда уходит разрушение, если либидо направлено на потребление? Тогда и становится понятной необходимость профессии, труда, трудовой этики, признания, семьи как форм жесточайшей дисциплины и насилия над собой, иначе кайфа потребления просто не будет. Люди, живущие и отдыхающие в Ницце и Сан-Тропе, отдыхают в таких условиях, что они сами или поколения перед ними получали кайф не от отдыха, а от призвания. Для меня лично как для носителя другой культурной парадигмы бо́льшим кайфом всегда была тема отдыха, праздности, а смысл успешной протестантской экономической жизни совершенно в другом. Принять эту истину в силу сложившихся традиционных стереотипов практически невозможно. Ведь неправильно понятый «день седьмый» и есть основание для замирания деятельности, ложно понятый смысл, ведь на самом деле деятельность не для отдыха и не для замирания.

Необходимо уточнить, что принятие решений чаще всего не имеет никакого отношения к рациональному выбору. У каждого человека есть опыт, сложность заключается в том, извлечен этот опыт или нет. Если мы говорим в понятийной структуре нашей статьи, то опыт отнесен к прошлому, а не к понятию «современность». Опыт есть знание апостериори, но только в том случае, если оно извлечено как знание суждения, а не знание убеждения. Если речь идет об убеждении, любая рациональная конструкция становится невозможной, так как смыслы в убеждении закрыты субъективным опытом, а не объективным переживанием действительности. Возникает тема убаюкивания себя, чтобы не воспринимать картину мира такой, какая она есть на самом деле. Субъективный опыт выступает в качестве своеобразной машины времени, которая откатывает событийную канву в прошлое, уменьшая боль от соприкосновения с реальностью. На первый взгляд 
все вроде бы в порядке, но ты упустил реальную жизнь и реальные события. Могущество современности в нахождении в здесь и в сейчас объективного мира, а это всегда больно и дискомфортно, потому что мы лишены сил по контролю реальности, баюкать себя вряд ли получится. Поэтому любые сказки о современности невозможны, в ней всегда действует принцип реальности, и не всегда ты на гребне волны, но держать себя на гребне волны - это и есть фоорма соответствия современности.

\section{СПИСОК ИСПОЛЬЗОВАННОЙ ЛИТЕРАТУРЫ}

1. Гегель Г. В. Ф. Наука логики : в 3 т. : пер. с нем. / Г. В. Ф. Гегель. - М. : Мысль, 1970. - Т. 1. - 502 с.

2. Гегель Г. В. Ф. Феноменология духа : пер. с нем. / Г. В. Ф. Гегель. - СПб. : Наука, 2006. - 444 с.

3. Кожев А. Введение в чтение Гегеля / А. Кожев. - СПб. : Наука, 2013. - 792 с.

4. Stiegler B. Pharmacology of Desire: Drive-Based Capitalism and Libidinal Dis-economy / B. Stiegler // New Formations. - 2011. - Iss. 72. - P. 150-161.

5. Мазин В. Незнайка и космос капитализма / В. Мазин, А. Погребняк. - М. : Изд-во Ин-та Гайдара, 2016. $-318 \mathrm{c}$.

6. Хоркхаймер М. Диалектика просвещения / М. Хоркхаймер, Т. Адорно. - СПб. : Медиум-Ювента, 1997. $-312 \mathrm{c}$.

7. Фуко М. Психиатрическая власть / М. Фуко. - СПб. : Наука, 2007. - 450 с.

8. Атанов А. А. Экономика концептов / А. А. Атанов. - Иркутск : Изд-во БГУЭП, 2008. - 400 с.

9. Дильтей В. Воззрение на мир и исследование человека со времен Возрождения и Реформации / В. Дильтей. - М. ; Иерусалим : Унив. кн., 2000. - 464 с.

10. Вебер М. Избранное: Протестантская этика и дух капитализма : пер. с нем. / М. Вебер. - М. ; СПб. : Центр гуманитар. инициатив, 2015. - 656 с.

\section{REFERENCES}

1. Hegel G. W. F. Wissenschaft der Logik. Nuremberg, Johann Leonhard Schrag, 1812. 1593 S. (Russ. ed.: Hegel G. W. F. Nauka logiki. Moscow, Mysl' Publ., 1970. Vol. 1. 502 p.).

2. Hegel G. W. F. System der Wissenschaft. Erster Teil, die Phnomenologie des Geistes. Bamberg und Würzburg, 1807. (Russ. ed.: Hegel G. W. F. Fenomenologiya dukha. Saint Petersburg, Nauka Publ., 2006. 444 p.).

3. Kozhev A. Vvedenie $v$ chtenie Gegelya [Introduction to Reading Hegel]. Saint Petersburg, Nauka Publ., 2013. $792 \mathrm{p}$.

4. Stiegler B. Pharmacology of desire: drive-based capitalism and libidinal dis-economy. New Formations, 2011, iss. 72 , pp. $150-161$.

5. Mazin V., Pogrebnyak A. Neznaika i kosmos kapitalizma [Neznaika and the Outer Space of Capitalism]. Moscow, Gaidar Institute Publ., 2016. 318 p.

6. Horkheimer M., Adorno T. W. Dialektik der Aufklaerung: Philosophische Fragmente. Frankfurt am Main, 1947. 294 S. (Russ. ed.: Horkheimer M., Adorno T. W. Dialektika prosveshcheniya. Saint Petersburg, MediumYuventa Publ., 1997. 312 p.).

7. Foucault M. Le pouvoir psychiatrique. Cours au Collge de France. 1973-1974. Paris, Gallimard, 2003, 393 p. (Russ. ed.: Fuko M. Psikhiatricheskaya vlast'. Saint Petersburg, Nauka Publ., 2007. 450 p.).

8. Atanov A. A. Ekonomika kontseptov [Economics of Concepts]. Irkutsk, Baikal State University of Economics and Law Publ., 2008. 400 p.

9. Dil'tei V. Vozzrenie na mir $i$ issledovanie cheloveka so vremen Vozrozhdeniya i Reformatsii [View of the World and Study of Man from the Renaissance and Reformation]. Moscow, lerusalim, Universitetskaya kniga Publ., 2000. $464 \mathrm{p}$.

10. Weber M. The Protestant Ethic and the Spirit of Capitalism. London \& Boston, Unwin Hyman, 1930. 292 p. (Russ. ed.: Weber M. Izbrannoe: Protestantskaya etika i dukh kapitalizma. Moscow, Saint Petersburg, Center for Humanitarian Initiatives Publ., 2015. 656 p.).

\section{Информация об авторе}

Атанов Андрей Алексеевич - доктор фрилософских наук, профессор, заведующий кафедрой философии, Байкальский государственный университет, 664003, г. Иркутск, ул. Ленина, 11, e-mail: andy777755@mail.ru.

\section{Для цитирования}

Атанов А. А. Детерминанты смысла концепта «современная экономика» / А. А. Атанов // Известия Байкальского государственного университета. - 2017. - T. 27, № 3. - C. 341-349. - DOI: $10.17150 / 2500-2759.2017 .27(3) .341-349$.

\section{Author}

Andrei A. Atanov - DSc in Philosophy, Professor, Head of the Department of Philosophy, Baikal State University, 11 Lenin St., 664003, Irkutsk, Russian Federation, e-mail: andy777755@mail.ru.

\section{For Citation}

Atanov A. A. Determinants of Sense of the "Modern Economy» Concept. Izvestiya Baykal'skogo gosudarstvennogo universiteta = Bulletin of Baikal State University, 2017, vol. 27, no. 3, pp. 341-349. DOI: 10.17150/2500-2759.2017.27(3).341-349. (In Russian). 